\title{
Os Porões da República: A colônia Correcional de Dois Rios entre 1908 e 1930
}

\author{
Myrian Sepúlveda dos Santos
}

\section{Introdução: 0 Isolamento dos Indesejáveis}

A Ilha Grande, segunda maior ilha oceânica do Brasil, fica a $150 \mathrm{~km}$ do Rio de Janeiro e a $400 \mathrm{~km}$ de São Paulo, dois grandes centros urbanos. ${ }^{1}$ Nos séculos anteriores, a condição de isolamento da Ilha Grande propiciou proteção e liberdade para aqueles que procuravam refúgio da ordem instituída. As histórias mais antigas da Ilha envolvem relatos sobre a ocupação daquele território por tamoios, piratas e mercadores ilegais de escravos. ${ }^{2}$ Ao longo do século XX, entretanto, uma transformação importante aconteceu, pois de refúgio a ilha tornou-se o lugar de suplício dos que ameaçavam a lei. Não só as autoridades passaram a ter controle sobre lugares mais distantes, como os colocavam à sua disposição para o controle da ordem.

As autoridades brasileiras, acompanhando tendências observadas em diversas partes do mundo, de estabelecer complexos correcionais e penitenciários em lugares de difícil acesso, criaram diversas instituições penais na Ilha Grande ao longo do último século. A Colônia Correcional de Dois Rios (CCDR) foi instalada em 1894 e a Penitenciária Cândido Mendes foi desativada em $1994 .{ }^{3}$ Nesse período, foram várias as medidas correcionais e punitivas adotadas. Nas três primeiras décadas, a Colônia Correcional de Dois Rios teve como objetivo principal aprisionar bêbados, mendigos, vadios e capoeiras; entre 1930 e 1964, Colônias Agrícolas foram instaladas para que os sentenciados pudessem cumprir o período final de suas penas; e a partir de 1964, o Instituto Penal Cândido Mendes tornou-se uma penitenciária de segurança máxima, mantendo no local os 
indivíduos considerados mais perigosos à sociedade. Durante todo esse período, estas instituições foram também utilizadas como prisão política.

Nos primeiros anos, o maior isolamento oferecido pela ilha assegurou um controle mais efetivo sobre os detidos durante um grande período. A comunicação com o mundo exterior era praticamente inexistente e o poder das autoridades locais imenso. A partir da década de 1970, entretanto, a construção da estrada Rio-Santos diminuiu a distância entre Angra dos Reis e as grandes capitais, facilitando fugas e maior comunicação com o mudo externo. ${ }^{4} \mathrm{O}$ processo de redemocratização e a maior liberdade adquirida pela imprensa minaram a autonomia e poder dos agentes penitenciários locais. Membros da Igreja Católica e de organizações voltadas para a defesa dos direitos humanos passaram a denunciar sistematicamente o tratamento bárbaro a que eram submetidos os presos. As fugas crescentes, o desvio de verbas públicas e a corrupção entre funcionários levaram à desativação e implosão do complexo em 1994.

Mas, como vimos, para as autoridades do início do século, a Ilha Grande era sinônimo de isolamento e representava a possibilidade de controle da ordem. Embora a CCDR tenha sido criada em 1894 para a correção de pequenos contraventores, as autoridades, inicialmente, não reconheceram sua importância e os investimentos realizados pelo Estado fracassaram. ${ }^{5}$ A partir de 1908, entretanto, a Colônia consolidou-se enquanto parte do sistema penal. Foram destinados para o local mais verbas, funcionários especializados, e um número crescente de detentos. O objetivo deste estudo é justamente o de privilegiar a análise da consolidação do sistema correcional na Ilha Grande ocorrida entre 1908 e 1930. Distante do objetivo declarado de recuperar os contraventores, a Colônia se caracterizou por isolar indivíduos, em sua grande maioria, pobres, negros, desassistidos, e que morriam em poucos meses de doenças resultantes de má alimentação e falta de higiene, como beribéri e disenteria. Além disso, à medida que manifestações de ruas e organizações políticas melhor se organizaram, a CCDR passou a receber não apenas indivíduos sem renda ou residência fixa, mas um número crescente de manifestantes políticos. Como veremos, inicialmente, ampliou-se o conceito de contravenção de modo que manifestantes políticos pudessem ser presos, sendo que, a partir dos anos 1920, novas leis e formas de repressão foram criadas. 


\section{A Distância entre Leis e Práticas}

Poucos meses após a posse de Afonso Pena, em março de 1907, foi realizada uma grande reforma nas forças policiais do Distrito Federal. ${ }^{6}$ Procurou-se profissionalizar o trabalho dos novos comissários, que passaram a ser recrutados através de concursos. Além disso, reorganizou-se a estrutura do Serviço Policial. O Chefe de Polícia, nomeado pelo Presidente da República, continuava com bastante poder na administração central e passava a ser auxiliado por três delegados, sendo que um deles assumia diretamente a responsabilidade de controle da Colônia Correcional de Dois Rios. A possibilidade de viabilizar os objetivos do estabelecimento enquanto colônia correcional dependia em grande parte do Chefe de Polícia. Ele possuía não só o controle de grande parte do processo contra os contraventores, decidindo quem seria enviado para a Colônia, como era o responsável pelas comissões de inspeção, capazes de averiguar as denúncias de corrupção, maus tratos e verificar se os regulamentos e ordens em vigor eram observados.

Logo após a reforma policial, em 1908, foi decretado um novo regulamento voltado para a reorganização da CCDR, estabelecendo regras rígidas para a vida administrativa da Colônia e uniformização da jurisprudência. ${ }^{7} \mathrm{O}$ objetivo declarado era o de desenvolver hábitos de autocoerção nos internos, proporcionando a eles sua recuperação espiritual e moral. $\mathrm{O}$ novo decreto regulamentava os vencimentos dos funcionários e destinava mais verbas à instituição correcional, possibilitando a realização de obras e aquisição de mobílias, equipamentos, máquinas, veículos terrestres e marítimos, bem como de sementes, animais, forragens, ferragens e arreamento. Foram reconstruídos alguns edifícios e instaladas práticas agrícolas e oficinas de trabalho. Estas reformas eram de extrema necessidade, uma vez que os prédios da Colônia, inclusive aqueles onde ficavam os contraventores, eram antigos e oriundos de uma antiga fazenda, sendo, portanto, totalmente impróprios às novas atividades.

$\mathrm{O}$ regulamento foi ainda bastante específico em relação à disciplina. Os internos deveriam ser separados em cinco grupos incomunicáveis: homens, mulheres, homens alcoólatras, mulheres alcoólatras e menores entre 14 e 21 anos. $\mathrm{O}$ alcoolismo representava um fator diferencial de desta- 
que. As penas disciplinares que foram estabelecidas para todos os tipos de internos reduziam-se a apenas três tipos: advertência, trabalho forçado e reclusão em cela. Estabelecia-se como obrigatório o trabalho, que deveria ser realizado por turmas diurnas na produção agrícola, pesca, criação de animais e oficinas de carpintaria, serraria, ferraria, sapataria, olaria e alfaiataria.

Além de procurar retirar do Estado o ônus pela sua manutenção, a Colônia precisaria cumprir a lei formando um pecúlio para os internos que fossem para lá enviados, de modo a que os internos pudessem se reintegrar à sociedade após a liberdade. Este pecúlio seria instituído em nome de cada interno, que teria direito a ele à medida que obtivesse comportamento exemplar, atestado pelo diretor e pelo chefe de polícia. As leis determinavam, ainda, a instalação de uma escola para instrução de filhos de funcionários e de correcionais.

O regulamento trazia disposições detalhadas sobre o funcionamento da Colônia Livre de Trabalhadores, que deveria ser composta por aqueles que tivessem cumprido pena e se encontrassem sem recursos para o trabalho ao deixarem a Casa de Correção, a Casa de Detenção ou a própria Colônia Correcional. Os colonos livres receberiam inicialmente vestimenta e alimentos da administração da Colônia, terra necessária para cultura de cereais e um terço da produção. Após o primeiro ano, o colono teria o direito ao arrendamento das terras mediante uma pequena indenização anual à Colônia.

A partir de 1908, portanto, a Colônia se estabeleceu como não havia sido possível nos períodos anteriores, recebendo maior número de funcionários especializados, verbas e uma regulamentação maior sobre castigos e benefícios. As prisóes localizadas no centro urbano se encontravam superlotadas e não eram mais capazes de resolver o problema da desordem; pequenos infratores, presos por períodos curtos de um a três meses, acabavam por retornar às celas. A CCDR tornou-se uma solução. Os chefes de polícia passaram a encaminhar para a Colônia um número maior de contraventores, de um modo geral, reincidentes e com penas maiores a cumprir, possibilitando, desta forma, que o complexo se tornasse auto-suficiente. O número de internos, na Colônia, que girava em torno de cem, 
entre 1902 e 1905, multiplicou-se rapidamente, sendo que, em 1909, já se apontava o problema da superlotação em Dois Rios. ${ }^{8}$

Não obstante os resultados satisfatórios presentes em relatórios oficiais relativos aos anos de 1908 e 1909, devido à instalação de algumas horticulturas, atividades de pesca e oficinas (ferraria, carpintaria, marcenaria e serraria), a CCDR esteve longe de cumprir os dispositivos da lei. Os relatórios ministeriais dos anos seguintes logo passaram a assinalar dificuldades de toda ordem. A manutenção das edificações e de um corpo de funcionários especializado continuava deficiente. A alimentação era precária, as doenças, constantes, e as condições de higiene, indignas. A separação de internos de acordo com idade, sexo e contravenção era praticamente impossível, pois os presos amontoavam-se em ambientes coletivos e utilizavam diversas dependências, como cozinha, lavatório e lavanderia, comuns. ${ }^{9}$

Em diversos ofícios dirigidos ao Chefe de Polícia, os diretores da Colônia solicitavam que para lá não fossem enviados jovens, mulheres e doentes, uma vez que não era possível controlar estes grupos e tratá-los adequadamente. Em 25 de agosto de 1920, o diretor Benvindo Meira, em ofício ao Chefe de Polícia, Geminiano da França, assim relatava o problema:

Existem presentemente nesta Colônia 34 menores cujas idades variam de 8 a 18 anos, quando o número deles tem sido, constantemente, muito maior. (...) O parágrafo $6^{\circ}$. do artigo 52 do regulamento que rege esta Colônia diz que os menores não serão aqui recolhidos, e sim a estabelecimentos industriais ou de regeneração mantidos pelo Estado ou pela iniciativa privada. (...) muitos aqui chegam doentes, tuberculosos e com sífilis, sem terem sido examinados antes de aqui chegarem, pervertendo e inoculando, assim, o vírus nos outros, no alojamento. (...) os correcionais procurando iludir a vigilância dos guardas nas próprias oficinas onde trabalham, embora separados dos menores, tentam por todos os meios seduzi-los, pois, muitas vezes, nem os animais escapam das garras desses perversos. (...) esta ilha tem muitas léguas de circunferência, cheia de montanhas, cachoeiras, florestas e pedreiras e os correcionais trabalham soltos no campo, mal fiscalizados à falta de guardas, e de praças de polícia (...) Por estes motivos me parece que V.Ex. justiceira como é, concordará em não consentir que continuem a vir menores para esta Colônia, porque aqui eles nem se educam, nem se preparam para o trabalho. ${ }^{10}$ 
A violência e impunidade dos guardas apareciam em artigos de jornais e processos. $\mathrm{O}$ isolamento do local parece ter sempre dificultado o controle do Estado sobre as práticas violentas dos guardas. Muitos são os processos arquivados a partir de denúncias de espancamentos e mortes. Em 1920, um processo foi formado a partir da denúncia do correcional Lourenço da Silva Campos, registrada pela polícia de Angra dos Reis, de ter sido espancado barbaramente pelos guardas, sob a liderança de um deles, Octavio Raymundo de Macedo, ficando de cama cinco dias. O diretor enviou um ofício ao Chefe de Polícia afirmando que o correcional, após ferir o faxina do seu alojamento, fora ferido pelos outros correcionais e não pelos guardas. Acrescentou, ainda, que os correcionais que espancaram o réu, em defesa do faxina, já tinham cumprido pena e estavam à disposição da lei. ${ }^{11}$

As fugas também fizeram parte da história das instituições carcerárias da Ilha Grande, uma vez que o sistema de trabalho semilivre permitia uma movimentação e liberdade maior dos internos, que procuravam escapar para praias vizinhas e lá roubarem um barco ou seqüestrarem um pescador para chegarem ao continente. As autoridades locais incentivavam os moradores da Ilha a participarem indiretamente do sistema de vigilância, sendo que muitos deles andavam armados regularmente e contavam com a recompensa oferecida pelas instituições carcerárias para completarem seu orçamento.

O anúncio publicado na Gazeta de Angra, de 6 de junho de 1920, exemplifica bem a prática existente:

Aviso aos senhores moradores de Caixa d'Água, Palmas, Abraão, Parnaióca, Sítio Forte e outras praias da Ilha Grande (em número de 35 aproximadamente). Darei uma gratificação de $25 \$ 000$ a quem prender e trouxer a esta Colônia qualquer correcional que tiver fugido. Eles vestem roupa azul e têm o número do lado do peito esquerdo. Não levam armas, nem são criminosos. Estão cumprindo pena por vadiagem, bebedeira e outros pequenos delitos. B. Meira, Diretor. ${ }^{12}$

São várias as histórias de casos de fuga de presos da Ilha Grande, sendo que os que capturavam os presos, fossem eles guardas, pescadores ou pequenos agricultores, tornavam-se heróis. $\mathrm{Na}$ fuga, regras eram esta- 
belecidas à margem da lei legitimando a mais pura barbárie. ${ }^{13}$ Os correcionais ficavam presos, todos juntos, em grandes barracōes, cuja estrutura era ainda a das antigas senzalas. O trabalho externo era realizado em grandes turmas, em espaço aberto e mal fiscalizado. No convite à fuga e no ritual da captura, estabelecia-se um sistema de vigilância que tinha por base o terror, construído, portanto, de forma muito distinta daquele utilizado em instituições modernas, para recuperar os infratores, que tinham por base controle central, disciplina rígida, silêncio e isolamento em celas..$^{14}$

As declarações de óbito eram freqüentes e mostravam que muitos presos faleciam após poucos meses de internação. Morria-se de beribéri, disenteria, tuberculose, sífilis, ou seja, doenças resultantes da má alimentação, falta de higiene e maus tratos, que eram constantes e fora do controle da Justiça. Em uma carta de 1910, a mãe de um menor pede transferência dos restos mortais do filho, Arthur Peixoto, do cemitério da Colônia para a necrópole de São Francisco Xavier. Declara a mãe que seu filho morrera um mês depois de recluso na Colônia de febre remitente biliosa. Joaquim Marques de Lima, 81 anos, viúvo, preto, deu entrada na Colônia em abril de 1919, e faleceu de disenteria aguda em 16 de junho do ano seguinte. Uma senhora chamada Anacleta Maria da Costa, de cem anos de idade, classificada como preta, solteira, sem profissão, morrera no hospital da Colônia, de "marasmo senil". Outra senhora, de cento e quinze anos de idade, dita indigente, sem residência e sem "pessoa alguma por si," procedente da Santa Casa de Misericórdia, fora enviada para a Colônia, falecendo meses depois. ${ }^{15}$

Outro aspecto a ser destacado, e que faz parte da história, não só da CCDR, mas das prisões da Ilha Grande, diz respeito ao desvio de alimentos destinados aos presos. Novamente, o controle do Estado sobre autoridades locais era precário. ${ }^{16}$ Em carta de 16 de maio de 1920, o diretor Benvindo Meira enviou um ofício ao Chefe de Polícia do Distrito Federal, Desembargador Geminiano da Franca, declarando que não podia arcar com o custo da alimentação dos 658 correcionais e que, como a verba só comportava 570 deles, ou seja, 88 correcionais ou mendigos se alimentavam das sobras do rancho geral. Há, do mesmo período, uma carta do Comando da Brigada Policial do Distrito Federal denunciando a falta de 
alimentos para os praças que trabalham na CCDR. Durante o ano de 1920, foram várias as cartas do Ministério da Justiça e Negócios Interiores solicitando ao Chefe de Polícia do Distrito Federal, que, por sua vez, solicitava ao diretor da Colônia, notas fiscais e explicações sobre a contabilidade. Passava-se a exigir o telefone e endereço dos locais de compra e venda de mantimentos, bem como notas fiscais acompanhando os balancetes emitidos pela Colônia, pois a diretoria de contabilidade do Ministério não se satisfazia com a contabilidade apresentada. ${ }^{17}$ Neste contexto, é fácil compreender que nem os pecúlios foram feitos para os trabalhadores de forma regular, nem colonos livres representaram uma saída social ou econômica para aqueles que procuravam inserir-se na sociedade como trabalhadores após a prisão.

Em suma, a CCDR se consolidou no imaginário coletivo da nação como lugar de maldição e castigo, significando em pouco tempo uma ameaça aos que se colocavam contra a ordem. Aqueles que iam para a Ilha Grande desapareciam da visão dos habitantes da metrópole; muitos lá eram esquecidos ou morriam.

\section{A Marca e Exclusão Social do Preso}

A distância entre leis e práticas inegavelmente está associada no Brasil a diversos aspectos inerentes à formação da nação. Entre os que estudam prisões, este é um aspecto comumente ressaltado. ${ }^{18}$ Entre as causas levantadas, podemos citar, por exemplo, a economia periférica aos centros de maior poder econômico, incapaz, portanto, de viabilizar as demandas sociais; o estado centralizador e burocratizado e uma sociedade marcada por instituições e práticas que reforçam hierarquias sociais. Ainda assim, é importante ressaltar que as próprias leis trazem contradições internas, resultado de visões conflitantes entre os que detinham o poder, permitindo a manutenção de práticas diferenciadas.

Embora ainda pouco denunciadas, dada a importância que tiveram na repressão aos setores populares, as leis relativas à contravenção aplicavam-se apenas aos que não tinham renda e trabalho, tratando de forma diferenciada, portanto, os cidadãos brasileiros. ${ }^{19} \mathrm{De}$ acordo com o artigo 399 do Código Penal de 1890, o vadio só seria preso se não tivesse renda 
para se sustentar. ${ }^{20}$ Após 1940 , embora as leis relativas à contravenção tenham sido separadas do código penal, elas mantiveram o mesmo sentido. ${ }^{21}$ Considerando que o Brasil é um país em que o desemprego ou emprego informal sempre apareceu como característica estrutural, a atribuição ao indivíduo da responsabilidade legal por não ter renda fixa a declarar foi um importante instrumento de repressão a uma parcela grande da sociedade.

No início do século XX, as leis que penalizavam e encarceravam os bêbados e vadios estavam presentes em diversas partes do mundo. ${ }^{22} \mathrm{Em}$ um país pobre, no entanto, a dimensão adquirida por estas leis tornou-se imensa. Quando os presos chegavam ao Depósito de Presos, localizado no centro da cidade, as autoridades policiais tinham o poder de classificá-los e decidir seus destinos. Aqueles que eram julgados criminosos eram encaminhados à Casa de Correção para cumprirem suas sentenças. Mas estes eram poucos. A grande maioria era encarcerada nas instituições da época que cumpriam o papel de assistir aos necessitados. Entre elas estava a Colônia Correcional de Dois Rios. ${ }^{23}$

Distribuição dos indivíduos encarcerados no Depósito de Presos do DF - 1911

\begin{tabular}{|l|c|c|c|c|c|}
\hline & $\begin{array}{c}\text { Depósito de } \\
\text { Presos }\end{array}$ & $\begin{array}{c}\text { Hospital } \\
\text { Nacional } \\
\text { dos Alienados }\end{array}$ & $\begin{array}{c}\text { Asilo de } \\
\text { Menores } \\
\text { Abandonados }\end{array}$ & $\begin{array}{c}\text { Colônia } \\
\text { Correcional } \\
\text { de Dois Rios }\end{array}$ & $\begin{array}{c}\text { Asilo São } \\
\text { Francisco de } \\
\text { Assis }\end{array}$ \\
\hline homens & 762 & 174 & 165 & 174 \\
\hline mulheres & & 442 & 523 & 51 & 523 \\
\hline total & 4.004 & 1.204 & 697 & 216 & 697 \\
\hline
\end{tabular}

No Brasil, como em outros países da América Latina, o número de indivíduos desajustados à ordem e reprimidos pelo chefe de polícia era muito maior do que aquele representativo dos crimes mais graves. Operários pobres, alcoólatras, doentes mentais, prostitutas, mendigos, vadios e manifestantes passaram a ser alvo predileto das autoridades policiais que 
os enviavam para asilos, penitenciárias, hospícios e escolas correcionais, todos denunciados como locais de custódia, sofrimento e desqualificação social. Estas operaçôes tinham por base leis e regulamentos legitimados pela sociedade. Vejamos.

Dentre os aproximadamente quatro mil indivíduos que foram detidos no Depósito de Presos, em 1911, a grande maioria foi destinada ao Hospital Nacional dos Alienados, sendo um número significativo deles enviados ao Asilo de Menores Abandonados, e outro tanto à Colônia Correcional de Dois Rios. Em número insignificante, contavam-se os indigentes levados para o Asilo de São Francisco de Assis. Mais de oitenta por cento dos indivíduos encaminhados ao Hospital dos Alienados não eram classificados como doentes mentais, mas sim como alcoólatras. Cabe destacar, ainda, que diferentemente dos Estados Unidos, no Brasil, não foi criado um conjunto significativo de instituições voltado para minimizar a pobreza. ${ }^{24}$ Os mendigos eram considerados contraventores e enviados para hospícios e colônias correcionais. $\mathrm{O}$ sistema assistencialista aos mais pobres era precário, praticamente inexistente.

Os pobres no Brasil não eram reconhecidos enquanto tal, pois mendigos eram encaminhados para as instituiçôes voltadas para o controle da contravenção e da insanidade.

Segundo os regulamentos que regiam a CCDR, deveriam ser corrigidos nas suas dependências os contraventores. $\mathrm{O}$ significado de "contravenção" nunca foi bem definido pela lei, o que dava maior liberdade às autoridades policiais. O Código Penal de 1890 definiu como contraventores "aqueles que se encontrassem na ociosidade e mendicância voluntária ou que fossem provocadores de tumultos". Em 1893, surge a especificação de correção de reincidentes. Em 1903, os adjetivos vinculados aos indivíduos contraventores aumentaram consideravelmente. A grande novidade do Decreto 6.994, de 1908, foi o acréscimo às definiçōes anteriores da palavra desordeiro. ${ }^{25}$ Como veremos adiante, ao longo das décadas seguintes o número de presos políticos aumentou consideravelmente. 


\begin{tabular}{|c|c|}
\hline & $\begin{array}{l}\text { Definição de "contraventores" } \\
\text { a serem enviados à CCDR }\end{array}$ \\
\hline Código Penal de 1890 & Ociosos, mendigos e provocadores de tumultos \\
\hline Decreto 145,1893 & Vadios, vagabundos e capoeiras reincidentes \\
\hline Lei 947, 1902 & $\begin{array}{l}\text { Mendigos válidos, vagabundos ou vadios, capoeiras } \\
\text { e menores viciosos }\end{array}$ \\
\hline Decreto 4.753, 1903 & $\begin{array}{l}\text { Mendigos válidos, do sexo masculino, vagabundos ou } \\
\text { vadios, capoeiras, ébrios habituais, jogadores, ladrões, } \\
\text { praticantes do lenocínio e menores viciosos }\end{array}$ \\
\hline Decreto 6.994, 1908 & Vadios, mendigos válidos, capoeiras e desordeiros \\
\hline
\end{tabular}

Bêbados, mendigos, vadios, vagabundos, capoeiras e desordeiros, embora contraventores, poderiam ser enviados para outras instituições. $\mathrm{O}$ que pode ser constatado a partir dos registros examinados é que, para a Colônia, eram enviados os reincidentes e habituais, ou seja, aqueles que davam mais problemas às autoridades policiais. Além disso, ficavam presos na Colônia aqueles que não possuíam conhecimento entre as pessoas influentes. A prisão poderia ser evitada ou interrompida se um termo de fiança fosse feito em favor do condenado. Este foi o caso, por exemplo, de Ernani Pereira da Silva, que, apesar de condenado ao cumprimento da pena de dois anos de reclusão na Colônia Correcional, foi colocado em liberdade, graças à fiança de seu irmão Francisco Rodrigues Lopes. Era possível, ainda, solicitar habeas corpus para os detidos, sob a alegação da ilegalidade da prisão. Os pedidos eram muitos e, em alguns casos, bem sucedidos. Um telegrama de Benvindo Meira ao Chefe de Polícia explicita bem os critérios das prisões em Dois Rios:

Dentre os 15 presos extraordinários que vieram pelo Laguna ontem está o nome Nilo Vilhas, filho do falecido médico do Exército e praticante da diretoria geral dos correios, licenciado pela prova de nomeação. Diz ter mãe e está doente. Consulto se o devo por em liberdade. Saudaçóes. ${ }^{26}$ 
As declarações de óbito, assinaladas acima, descreviam os mortos como pessoas sem recursos e "sem pessoa alguma que pudesse olhar por si" e também evidenciam o desamparo em que se encontravam aqueles que eram enviados para a Colônia.

Em “Alma Encantadora das Ruas”, João do Rio ilustra bem esta condição de desamparo, ao relatar o desabafo de uma mulher que chegara de Dois Rios:

- Ah! Meu caro senhor, por piedade, peça ao ministro o meu perdão. Há três anos sofro. $\mathrm{O}$ ódio de um inspetor, a falta de amigos e de proteção reduziram-me a este lamentável estado. Venho da colônia. Não me trataram como uma presa, trataram-me como uma pessoa digna de piedade. $\mathrm{E}$ apesar disso eu estou assim. Perdão para mim! ${ }^{27}$

Além da margem de autonomia obtida pelas autoridades policiais através de utilização de classificações ambíguas, esta também foi resultado do próprio sistema legislativo. A partir da Lei Alfredo Pinto, decretada em 1899, a atuação dos delegados policiais foi extremamente fortalecida. ${ }^{28}$ Não obstante o caráter liberal do Código Penal, que atribuía à polícia apenas as tarefas de efetivar prisóes e abrir inquéritos, ela manteve o poder de conduzir os processos de contravenção, por longos períodos, cabendo ao Judiciário apenas a sentença final.

Vimos, portanto, que para além da impossibilidade de cumprimento das leis, as práticas brutais que caracterizaram o sistema carcerário em Dois Rios também se respaldavam em aspectos inerentes às próprias leis. $\mathrm{O}$ artigo 399 do Código Penal e a Lei Alfredo Pinto, entre diversas outras leis de exceção, autorizaram o arbítrio. Se o mendigo ou vadio tivesse algum conhecimento entre as pessoas de bem, escapava das punições mais severas. A lei estipulava o compadrio a partir de termos de compromisso. Estas observações são importantes porque mostram que juízes e autoridades policiais não ocupavam campos completamente antagônicos no estabelecimento da democracia republicana. Embora fosse inegável a disputa de poder entre eles, evidenciada no avanço ou recuo de leis que defendiam o habeas corpus, por exemplo, a prática de ambos demonstrava que o tratamento desigual dos cidadãos fazia parte da manutenção da ordem vigente.

A percepção entre as autoridades de que indivíduos deveriam ser tratados distintamente possibilitou, ainda, a aplicação diferenciada das leis, 
mesmo que estas tivessem um cunho universalizante. Classificações ambíguas e instrumentos de defesa não acessíveis a todos legitimavam a desigualdade que era imposta e consolidada. O pressuposto da desigualdade entre indivíduos, bastante naturalizado, fica bem marcado por um conjunto de pedidos formais encaminhados dos funcionários da Colônia a seu diretor, e deste ao Chefe de Polícia, solicitando autorização para que mendigas presas na Colônia pudessem ser entregues aos funcionários para serviços domésticos. Reproduzimos literalmente dois destes pedidos, um telegrama emitido em janeiro de 1918, e outro registro do encaminhamento dado pelo Diretor da Colônia ao Chefe de Polícia, em fevereiro de 1920:29

Peço autorização do diretor da Colônia Correcional Dois Rios para baixar a mendiga indigente Antonieta internada em 23 de dezembro de 1917 para minha criada. Escriturário Ribeiro

O senhor diretor da Colônia Correcional de Dois Rios solicita a S. Excelência o Dr. Chefe de Polícia a devida autorização a fim de ser entregue, ao telegrafista daquele estabelecimento, para serviços domésticos a mendiga Francisca Augusta Soares recolhida a Colônia em 23 de dezembro de 1917.

É importante registrar a menção constante a pretos em obituários e registros da CCDR. Não obstante o cunho liberal do Código Penal brasileiro, que respeitava o indivíduo de forma universal e como possuidor de uma consciência livre e soberana, o aparato político-institucional brasileiro foi fortemente influenciado por lideranças que defendiam idéias positivistas, que serviram para discriminar diferentes grupos sociais. A criminologia associava teses positivistas, cientificistas e biológicas e, enquanto tal, divulgada por revistas especializadas em legislação, doutrina e jurisprudência, como a revista $O$ Direito, difundida nas principais capitais e abertamente defendida por inúmeras autoridades republicanas. ${ }^{30} \mathrm{Na} E u-$ ropa, a associação entre traços de criminalidade e aspectos biológicos foi utilizada para discriminar imigrantes latinos; na Argentina, imigrantes italianos e espanhóis.

No Brasil, para muitos dos que reformularam o sistema penitenciário na década de 1920, entre eles Lemos Britto, um dos principais problemas a ser resolvido no Brasil seria justamente a vertente liberal do Código de 1890 , pois penas deveriam ser voltadas para os criminosos, determina- 
dos por condicionantes sociais e raciais, e não para os crimes. Atribuía-se, portanto, aos negros e mestiços uma tendência natural ao crime. ${ }^{31}$ Como a pobreza estava presente entre os negros e mestiços recém-libertos, as autoridades policiais não tiveram qualquer dificuldade em identificar negros-pobres como criminosos em potencial. As instituiçóes penais, e a CCDR entre elas, pois muitos dos seus primeiros diretores foram médicos voltados para práticas de classificação e recuperação moral, trataram indivíduos a partir de suas marcas raciais e sócio-culturais.

Como as penalidades mais severas não eram estipuladas pela lei, mas por práticas de violência cotidiana, os negros e pobres pagavam com a vida penas que, segundo a lei, deveriam ser cumpridas em poucas semanas de prisão simples. Os internos não tinham qualquer comunicação com amigos e familiares e os guardas locais detinham uma autonomia exacerbada. A falta de controle do Estado sobre os administradores da Colônia implicava desvio e, portanto, privação de alimentos, tratamento violento e manutenção dos internos na prisão sem sentenças e após o cumprimento da pena.

O aspecto perverso do sistema jurídico-penal moderno está em que as instituições penais operam ainda hoje de forma antagônica a seu discurso. Os dados sobre os maus-tratos, desrespeito, condições duras de sobrevivência nos mostram que a CCDR, por exemplo, não propiciava a recuperação de ninguém. Ao contrário, condenava, através da marca da prisão, todos os que para lá eram enviados a se tornarem párias sociais. $\mathrm{O}$ estigma de ter passado pela ilha da maldição dificilmente era superado pelos internos. ${ }^{32}$

A CCDR, entretanto, não foi uma prisão apenas de contraventores sociais. A classificação ambígua de contravenção permitiu que, quando necessário, presos políticos fossem reprimidos sob o mesmo teto e através das mesmas medidas repressoras. A tentativa de desqualificar os presos pela humilhação e maus-tratos foi rechaçada por manifestantes políticos, muitos deles oriundos das classes mais abastadas, de forma mais enérgica. A partir da década de 1920, uma nova legislação foi criada com o intuito de tornar mais efetiva a repressão política, voltando, no final da década, a Ilha Grande a ser cárcere prioritariamente dos desamparados sociais. 


\section{0 Início do Cerco aos Manifestantes Políticos}

A partir de 1910, o número de internos da Colônia diminuiu. Os Chefes de Polícia alegavam perda de autoridade frente ao Poder Judiciário. Segundo eles, tornara-se impossível prender vagabundos como era necessário, pois os juízes não julgavam culpados aqueles que eram presos pelos policiais, absolvendo-os sistematicamente e em grandes números. ${ }^{33}$

Em 1912, o Chefe de Polícia apresentou um relatório ao Ministro da Justiça e Negócios Interiores criticando duramente a Colônia pelo estado precário do estabelecimento, terras impróprias à agricultura, não cumprimento dos objetivos correcionais e falta de fiscalização devido à distância. ${ }^{34}$ No ano seguinte, após uma visita de inspeção feita à Colônia pelo Ministro da Justiça e Negócios Interiores, Dr. Herculano de Freitas, acompanhado do Chefe de Polícia, Francisco de Campos Valadares, novas críticas foram feitas ao estado físico e funcionamento do estabelecimento. A comissão sugeriu, reiterando críticas anteriores à impropriedade do local, que o estabelecimento deveria ser removido para uma região mais próxima ao Distrito Federal. $\mathrm{O}$ isolamento era apontado como pernicioso ao funcionamento geral do presídio, havendo denúncias, principalmente, de deterioração e ruína das instalações e serviços, impróprios para receberem os correcionais. ${ }^{35}$

O perfil dos contraventores, a partir de 1910, modificou-se bastante, uma vez que houve um aumento grande do número de homens detidos. Diferentemente dos primeiros anos da CCDR, quando em alguns períodos o número de mulheres ultrapassava o de homens, nesta fase os que eram enviados para a Colônia eram indivíduos majoritariamente do sexo masculino.

\begin{tabular}{|l|c|c|c|c|c|c|c|}
\hline \multicolumn{7}{|c|}{ Número de Internos na CCDR entre 1908 e $1914^{36}$} \\
\hline & 1908 & 1909 & 1910 & 1911 & 1912 & 1913 & 1914 \\
\hline correcionais & 490 & 551 & 250 & 221 & 345 & 361 & 240 \\
\hline $\begin{array}{l}\text { colonos } \\
\text { livres }\end{array}$ & 21 & 2 & & & & & \\
\hline $\begin{array}{l}\text { marinheiros e } \\
\text { soldados navais }\end{array}$ & & & & 94 & & & \\
\hline
\end{tabular}


Uma mudança radical aconteceu a partir de 1914. A CCDR, ocupando as mesmas edificações precárias que foram reconstruídas em 1908, manteve sob seu teto, no ano de 1917, pela primeira vez em sua história, mais de mil "correcionais", número próximo aos de presos que eram encarcerados na Casa de Detenção, no Distrito Federal. Sua importância para as forças governamentais responsáveis por estabelecer a ordem assumia grandes proporções.

Entre 1914 e 1918, portanto, o número de internos da Colônia aumentou bastante, o que coincidia com o aumento das manifestaçôes sociais e políticas nas ruas da capital federal. Esta passava a receber um contingente cada vez maior de estrangeiros, anarquistas, comunistas e operários. Wenceslau Braz, ao assumir a presidência, enfrentou uma grave crise econômica em conseqüência da Primeira Guerra Mundial. Em 1917, manifestações anarquistas e comunistas se organizavam contra baixos salários e condições precárias de trabalho. Houve uma forte repressão aos movimentos contrários ao governo. O Chefe de Polícia Aurelino Leal implantou uma nova reforma nas forças policiais de forma a torná-las mais ágeis e capazes de efetuar as prisóes políticas. ${ }^{37} \mathrm{O}$ Corpo de Investigação e Segurança Pública foi fortalecido através de leis orçamentárias. ${ }^{38}$ As organizações operárias foram fechadas e os seus membros foram mortos, presos, deportados para regiōes longínquas e expulsos do território brasileiro. Entre outubro e novembro de 1917, o Lazareto da Ilha Grande foi transferido para o Ministério da Marinha, assumindo funções de presídio, como resultado da declaração de guerra do Brasil à Alemanha. ${ }^{39}$

\begin{tabular}{|l|c|c|c|c|c|}
\hline \multicolumn{6}{|c|}{ Número de Internos na CCDR entre 1915 e $1919^{40}$} \\
\hline & 1915 & 1916 & 1917 & 1918 & 1919 \\
\hline Homens & 482 & 636 & 1.056 & 996 & 492 \\
\hline Mulheres & 122 & 127 & 161 & 154 & 99 \\
\hline $\begin{array}{l}\text { No de } \\
\text { correcionais }\end{array}$ & 604 & 763 & 1.217 & 1.150 & 877 \\
\hline
\end{tabular}


Apesar da mudança do perfil do interno, o discurso sobre o papel regenerador do trabalho se mantinha. Os diretores das instituições prisionais, muitas vezes bacharéis de direito, defendiam publicamente a obrigatoriedade do trabalho, sob a alegação de que ele propiciaria uma fonte de receita para a instituição, pecúlio para o preso posto em liberdade e, principalmente, hábitos salutares e regeneração moral. ${ }^{41}$

O alto custo da manutenção da CCDR, resultado da distância e isolamento, foi sempre um aspecto enfatizado pelas autoridades nas avaliações do estabelecimento. Contudo, uma análise comparativa entre os gastos realizados pelas diversas instituiçóes carcerárias do período nos mostra que a falta de verbas não poderia ser a única explicação para as condições precárias encontradas na Colônia. As despesas com a manutenção da CCDR eram baixas para os cofres públicos se comparadas a outras instituiçôes carcerárias; bem menores, por exemplo, do que aquelas destinadas à manutenção da Casa de Detenção e, até mesmo, do que era aplicado na Casa de Correção. Esta última abrigava pouco mais de 200 presos cumprindo penas por homicídio, roubo, agressões corporais e outros crimes.

\begin{tabular}{|c|c|c|c|}
\hline \multicolumn{4}{|c|}{ Orçamento estimado para o ano de 191942 } \\
\hline Estabelecimento & Casa de Detenção & Casa de Correção & $\begin{array}{c}\text { Colônia Correcional } \\
\text { de Dois Rios }\end{array}$ \\
\hline Número de internos & 1.246 presos & 237 condenados & 1.217 correcionais \\
\hline Orçamento Previsto & $778: 040 \$ 139$ & $385: 022 \$ 388$ & $260: 900 \$ 000$ \\
\hline Custo por interno & $624 \$ 430$ & $1: 624 \$ 567$ & $214 \$ 380$ \\
\hline
\end{tabular}

Provavelmente a Colônia não foi removida, desativada ou mesmo reconstruída, conforme as indicações de várias inspetorias, porque interessava às autoridades seu aspecto de masmorra, fator que deveria contribuir para o controle da ordem. A travessia marítima nauseante, o isolamento, as edificações deterioradas, a falta de condiçôes de higiene e privacidade, a promiscuidade, a violência entre presos e a arbitrariedade das punições possibilitaram a construção da imagem da CCDR como lugar maldito a ser temido e evitado. 


\section{A Regulamentação das Prisões Políticas}

A partir do governo de Epitácio Pessoa, inúmeras leis foram decretadas visando uniformizar e regulamentar a repressão política. ${ }^{43}$ Segundo o Ministro Alfredo Pinto, o governo necessitava urgentemente de leis repressivas para permitir a profilaxia social. Para que indesejáveis fossem punidos, eram necessários os elementos da ordem jurídica. ${ }^{44}$

Ressaltando a importância das classificaçōes, faz notar que:

E ao simples relancear dos títulos em que se definem as espécies criminais, logo notamos que aí não se encontram várias modalidades de ação delituosa, nas quais se desdobram hoje, por exemplo, os crimes de moeda falsa, de lenocínio, de ofensa à moral pública ou surgem novas formas de criminalidade sectária a exemplo do anarquismo violento e destruidor. ${ }^{45}$

Alfredo Pinto criticava o caráter liberal das leis e defendia a tarefa de centralizar, disciplinar e unificar métodos necessários à gestão pública, apontando a urgência de reformas no sistema policial, jurídico, de ensino e de saúde. As novas leis regulamentaram, com maior eficiência, a expulsão de estrangeiros, as associações públicas, proibindo as que não fossem de interesse do governo, e o controle da imprensa. Foram criados instrumentos legais contra os crimes de injúria e de calúnia, o que permitiu ao governo melhor controlar as agitaçôes sociais e políticas.

Embora a prisão de manifestantes políticos tenha se tornado uma prática rotineira nos anos que se seguiram, ${ }^{46}$ houve a tentativa de imprimir alguma racionalidade à concessão do livramento condicional e indul-

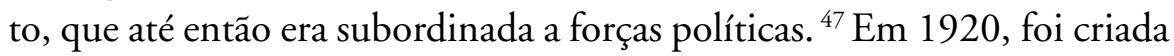
a Inspetoria de Investigações e Segurança Pública, órgão que exerceu a função de polícia política. ${ }^{48}$ A União Geral dos Trabalhadores do Rio de Janeiro foi dissolvida em 1919, e o Partido Comunista Brasileiro (PCB) foi fundado em 1922.

No que tange às instituições carcerárias, foi decretado, em 1919, um regulamento para uniformizar procedimentos. ${ }^{49}$ Os novos regulamentos definiram de forma mais específica o tratamento adequado que deveria ser dado às mulheres e aos menores, sendo criados estabelecimentos separados para eles. Em 1921, estabeleceram-se critérios mais detalhados para 
classificar os "menores," que passavam a estar sujeitos às disciplinas impostas por colônias correcionais, escolas de menores abandonados e patronatos agrícolas. ${ }^{50}$ A partir de 1922, o Patronato das presas empenhouse em conseguir um estabelecimento penal especializado. Em 1922, foi criado pela primeira vez um órgão que teria a incumbência de supervisionar todo o sistema penitenciário da nação: a Inspetoria Geral das Prisões Federais. Foi também criado o cadastro penitenciário em todo o território nacional. ${ }^{51}$

As novas leis e regulamentos modificaram profundamente a situação em que se encontrava a CCDR. Em 1919, foram postos em liberdade diversos correcionais e "preventivos" da CCDR, sendo mantidos 877 internos. Nos anos subseqüentes, apesar dos movimentos de contestação ao regime e do aumento de prisões a manifestantes, o número de internos na Colônia diminuiu bastante. Em 1929, foram registrados apenas 221 correcionais na Colônia. Muitos dos internos deste período cumpriam penas pequenas, de três a seis meses, o que também nos leva a concluir que a CCDR voltava gradativamente a ser o local de destino dos ébrios e vadios da cidade do Rio de Janeiro, que, neste período, já não eram considerados tão perigosos à ordem pública. ${ }^{52}$

\begin{tabular}{|c|c|c|c|c|c|}
\hline \multicolumn{5}{|c|}{ Número de Internos na CCDR entre 1920 e 1929} \\
\hline & 1920 & 1921 & 1922 & 1923 & 1929 \\
\hline No de correcionais $^{\circ}$ & 877 & 548 & 647 & 562 & 562 \\
\hline
\end{tabular}

\section{A Multiplicação das Ilhas de Desterro: 1922-1930}

No relatório ministerial de 1923, apontava-se como sendo urgente a reforma da Colônia para que ela deixasse de ser um depósito de presos para tornar-se uma "verdadeira penitenciária". ${ }^{53}$ A partir de 1922, os relatórios anteriormente realizados por autoridades policiais sobre a CCDR deixaram de ser regulares e o número de contraventores enviados para a CCDR diminuiu significativamente. Como veremos a seguir, não obstante as denúncias realizadas à precariedade do estabelecimento, a diminuição de presos na CCDR teve outros motivos. 
As péssimas condições da CCDR não diferiam muito daquelas encontradas em outras prisões, que, em geral, eram consideradas pelos juristas da época como sendo deterioradas, superlotadas e necessitadas de grandes reformas. Em 1922, Lemos Britto fora encarregado pelo Ministro da Justiça, João Alves, da reforma penitenciária. Em 1924, ele diagnosticou como nefastas e odiosas as condições das prisóes de diversas capitais brasileiras. ${ }^{51} \mathrm{~A}$ diminuição de presos na Colônia também não foi resultado de um menor número de detenções na capital, pois as manifestações contrárias ao governo continuavam e as prisões ocorriam em grandes números.

Em julho de 1922, já no final de seu mandato, Epitácio Pessoa precisou conter forças do Exército, ordenando o fechamento do Clube Militar e a prisão de seu presidente, Marechal Hermes da Fonseca. Em resposta, houve uma série de levantes militares contra o governo, entre eles, no Rio de Janeiro, o dos 18 revoltosos do Forte de Copacabana, comandado por Siqueira Campos, que resultou em mortos e feridos. O presidente eleito, Arthur Bernardes, assumiu a presidência em novembro de 1922, em clima de conturbação social. Seus opositores, portanto, não eram os anarquistas e comunistas de 1917, mas os militares. Jovens oficiais, em nome da defesa ao nacionalismo, opunham-se ao poder das oligarquias de Minas Gerais e São Paulo, reivindicando um Estado centralizado, mais forte, capaz de proporcionar o voto secreto e um Poder Judiciário independente.

O novo aparato jurídico-institucional criado no governo de Epitácio Pessoa tornou possível uma repressão mais direcionada a movimentos políticos e sociais. Além disso, os estados de sítio permanentes permitiram que a atuação dos Chefes de Polícia se fortalecesse em relação ao Poder Judiciário, sendo permitidas prisóes sem que os acusados fossem levados a julgamento. Em novembro de 1922, o Decreto 15.848 deu amplos poderes às autoridades policiais. A chefatura de polícia deixava de ser entregue a um magistrado ou bacharel, conforme lei anterior, para ser confiada a um militar do Exército. Logo após a lei ser decretada, o presidente nomeou como Chefe de Polícia o Marechal Manoel Lopes Carneiro da Fontoura, habituado a métodos repressivos. $\mathrm{O}$ mesmo decreto criou a $4^{\mathrm{a}}$. Delegacia Auxiliar, de livre nomeação e demissão do Chefe de Polícia, para onde foram transferidos todos os serviços da antiga Inspetoria de Investigação e Segurança Pública. Carlos da Silva Reis, major da Polícia 
Militar, foi nomeado Chefe da $4^{a}$. Delegacia Auxiliar, com amplos poderes para investigar e prender os considerados indesejáveis.

A Seção de Ordem Social e Segurança Pública reprimia de forma efetiva estrangeiros e associações operárias, anarquistas e comunistas. Ela tinha como função:

... velar pela existência política e segurança interna da República, empregar os meios preventivos à manutenção da ordem, assegurar o livre exercício dos direitos individuais, desenvolver a máxima vigilância contra as manifestaçôes ou modalidades anárquicas e agir prontamente com relação à expulsão de estrangeiros perigosos. ${ }^{54}$

O poder de atuação das autoridades policiais investigava, controlava, classificava e prendia qualquer cidadão brasileiro ou estrangeiro que se opusesse ao regime. Em alguns casos, transeuntes e curiosos eram também presos, sem que lhes fosse dada a oportunidade de provar que não estavam envolvidos com os manifestantes, deportados, indo morrer em algum cárcere perdido nos confins do território nacional. A 4a . Delegacia, só no ano de 1923, com a finalidade de informar as autoridades policiais nos processos de naturalização e solicitação de serviços, fez o levantamento dos antecedentes de mais de 16 mil indivíduos suspeitos de crime político.

Em 1923, militares revoltosos foram julgados e condenados à prisão. ${ }^{55} \mathrm{~A}$ condenação propiciou novos levantes de militares. Os tenentistas, neste mesmo ano, reuniram-se aos revoltosos gaúchos, que também se organizavam contra o governo central, dando origem à Coluna Prestes. À medida que os movimentos de oposição se fortaleciam, o governo aprimorava seus métodos de repressão. Em São Paulo, em 1924, cerca de dez mil pessoas foram presas. Nos estados, praticamente todos aqueles que colaboraram com o movimento dos tenentes foram submetidos a processos. Foi também neste período que a Lei Adolfo Gordo foi aprovada, após permanecer dois anos em discussão no Congresso, estabelecendo restrições à liberdade de imprensa e atingindo as diversas formas de expressão de movimentos sociais e políticos. ${ }^{56}$

A importância da CCDR diminuiu à medida que uma legislação específica permitiu que presos políticos fossem enviados para outras prisões. Em 1923, o Chefe de Polícia criticava a deportação dos indivíduos 
absolutamente indesejáveis dos estados do norte do país para a Capital, tornando-a um centro de contraventores, solicitando a criação de novos estabelecimentos prisionais nas demais regiōes do país. ${ }^{57} \mathrm{Na}$ década de 1920 , estabelecimentos de diversos ministérios foram utilizados para manter presos militares em isolamento, o que era considerado um recurso legítimo pelos governantes republicanos, dados os diversos protestos que se sucediam na Capital Federal e a situação de estado de sítio em que se encontrava o país.

Os presos passaram a ser enviados por meio de navios-presídios para locais distantes e isolados. Diversas outras ilhas passaram a abrigar presídios, entre elas Ilha das Flores, Ilha de Bom Jesus, Ilha das Cobras e Ilha Trindade. A Ilha das Flores, estabelecimento do Ministério da Marinha situado na Baía de Guanabara, era capaz de alojar mais de mil pessoas. Entre os anos de 1924 e 1926, a Ilha da Trindade, próxima ao litoral do Espírito Santo, tornou-se prisão e recebeu oficiais, sargentos e praças envolvidos com o movimento tenentista, entre eles Eduardo Gomes e Juarez Távora. Em 1925, localizado bem próximo à CCDR, o Lazareto foi designado prisão militar preventiva. ${ }^{58} \mathrm{~A}$ repressão do governo foi sistemática e abrangente. Entre 1924 e 1925, centenas de presos foram enviadas para Clevelândia, ${ }^{59}$ no então território do Amapá. Após uma travessia descrita pelos que sobreviveram à experiência como martirizante, praticamente a metade dos deportados foi dizimada por uma epidemia de tifo, que se associou a condições insalubres e falta de tratamento adequado. Entre os presos, encontravam-se imigrantes, soldados, marinheiros, operários, anarquistas e comunistas, como também os que eram detidos por vagabundagem e mendicância. ${ }^{60}$

Conforme declaração do próprio Senador Miguel Calmon, em 1927:

(...) o governo só deportou para Cleveland em último caso e forçado pelos pedidos de habeas corpus ao Supremo Tribunal Federal, que não permitiam a conservação dos presos aqui. (...) os deportados para Cleveland foram presos que tinham os piores antecedentes e sem nenhum título especial que os recomendassem. ${ }^{61}$

Se havia alguma identidade entre os presos dos últimos governos republicanos, podemos dizer que certamente eram indivíduos pobres e sem acesso à Justiça. A Justiça continuava a operar de forma diferenciada. A 
Ilha Grande perdia importância como cárcere, pois já não causava mais o temor necessário. Cárceres bem mais ameaçadores e distantes foram criados no país.

\section{Conclusão}

A criação da Colônia Correcional de Dois Rios fez parte de um movimento de modernização do sistema jurídico-penal no Brasil, com características que foram observadas em diversas partes do mundo; procuravase recuperar indivíduos para o convívio social através da vigilância, disciplina e trabalho. A distância, entretanto, entre normas e práticas foi enorme.

As leis, fossem elas de inspiração liberal ou positivista, mantiveram uma distância bem grande em relação às práticas descritas nos estabelecimentos penais. A prisão em células individuais e voltada para a recuperação da autoconfiança do indivíduo sentenciado era uma quimera, tal qual a intervenção que tinha como objetivo recuperar moralmente os infratores. Os estabelecimentos penais não ofereciam condiçôes para que os princípios estabelecidos por leis fossem minimamente cumpridos. Em que pese os conflitos entre diversas visóes de crime e castigo ao longo das primeiras décadas da República, a CCDR foi utilizada como forma de ameaça aos que se colocavam contra o regime político estabelecido. Legitimou-se em detrimento de críticas generalizadas sobre a barbárie lá institucionalizada.

Frente ao hiato observado entre normas e práticas, autores procuraram as causas do problema em aspectos econômicos, políticos, sociais e culturais. A modernização brasileira, por ser periférica, envolveria instituiçôes pobres e deficientes, um governo centralizado e burocrático, uma sociedade patrimonialista, mediada por práticas marcadas pela cultura ibérica. Embora todos estes sejam aspectos que possam ser considerados, é importante lembrar que o hiato entre leis e práticas, principalmente no que diz respeito aos sistemas penitenciários, tem sido denunciado em países de maior desenvolvimento industrial e estabilidade democrática. Neste trabalho procurei enfatizar alguns aspectos que apontam o processo de modernização seletiva do sistema prisional desde seus primórdios. A pes- 
quisa nos mostra a presença de práticas de desqualificação e violência extremas, direcionadas principalmente às camadas sociais menos favorecidas, que representavam uma parte significativa da sociedade.

Dois Rios, como ficou conhecida a Colônia, foi criada para corrigir alcoólatras, desempregados, biscateiros, indivíduos doentes, trabalhadores pobres, mendigos, vagabundos, capoeiras, ladrões, cáftens e prostitutas. No início do período republicano, estes eram os indivíduos que ameaçavam as autoridades por se colocarem como peças fora da engrenagem. Eles não se adaptavam ao ideal construído de progresso e democracia. Exigia-se da população atributos nem sempre valorizados, como competição, trabalho, sucesso e excelência. $O$ progresso reivindicava do cidadão uma racionalidade que, embora dita natural ou universal, foi não só rejeitada, como encontrou resistência. A adequação da população à sociedade industrial fez-se a partir de uma guerra nas ruas e da exclusão, que tornava-se possível pela marca da marginalidade adquirida no interior das instituições carcerárias.

A Colônia deveria se voltar para a manutenção de um ambiente arejado, limpo e saudável, capaz de propiciar, através do trabalho e da disciplina, a recuperação da auto-estima e dos valores morais de cada um. $\mathrm{Na}$ prática, foi sede de práticas humilhantes, coercitivas e violentas. A partir de 1910, a população carcerária foi se modificando, pois a Colônia tornou-se útil no encarceramento de manifestantes políticos. Em épocas de crise, em que o número de prisóes era muito grande, utilizou-se também o Lazareto da Ilha Grande como prisão política e militar.

O esvaziamento da Colônia nos governos de Arthur Bernardes e Washington Luís coincidiu com a criação, por um lado, de uma legislação específica voltada para a repressão de estrangeiros, anarquistas e comunistas e, por outro, de um complexo penitenciário cujas características de barbárie conseguiram obscurecer a imagem de Dois Rios. Clevelândia ultrapassou os limites da imaginação.

O que a investigação destes porões da miséria nos mostra, portanto, é parte, ao mesmo tempo metáfora e metonímia, da história da República. Trata-se da manutenção de governos respaldados em estados de sítio e forças policiais que tinham o poder de colocar em isolamento e sob maustratos todos aqueles que não fossem desejáveis ou que se dispusessem con- 
tra o governo central. A Colônia cumpriu, inicialmente, o papel de amedrontar e isolar os bêbados e vagabundos da cidade, passando em pouco tempo a ser o terror de manifestantes políticos organizados.

Em suma, apesar das diversas críticas e denúncias, a situação precária das instalações e o tratamento indigno proporcionado aos internos mantiveram-se na CCDR durante todo o período analisado. Em 1927, o Chefe de Polícia, Dr. Coriolano de Araújo Góes Filho, resumiu bem as contradições do sistema jurídico-penal ao longo de 20 anos:

Não é preciso aditar considerações ao que consta de relatórios de alguns dos meus antecessores, em afirmativa de que, funcionando há mais de 20 anos, e pesando cerca de 800 contos anuais no orçamento, a Colônia Correcional de Dois Rios foge aos fins de emenda, de reabilitação integral ou relativa dos pacientes, além de ser ainda um presídio à antiga, rudimentar, estéril e mal visto pela opinião pública. (...) Um confronto do que estatui o decreto 6.994, de 19 de junho de 1908, que reorganizou a Colônia, com o que de fato existe ali e nas consignações da Despesa, obriga a concluir que se impõe a reforma completa do estabelecimento, partindo da preliminar da sua deslocação daquela ilha afastada. ${ }^{62}$

\section{Notas}

${ }^{1}$ Gostaria de agradecer ao CNPq e à UERJ pelo apoio à pesquisa e à contribuição dos seguintes bolsistas de iniciação científica: Carin Istravidris, Cíntia Aparecida Pereira Guimarães, Renata Bhering, Thaís Lemos Duarte e Thatiana SantAnna Gonçalves.

${ }^{2}$ As fontes secundárias relativas à história da Ilha Grande são muitas, embora poucas de caráter estritamente acadêmico. Duas delas, entretanto, merecem ser destacadas:.Lima 1889 e Mello 1987.

${ }^{3}$ Em 1884, o Lazareto da Ilha Grande foi construído com o objetivo de isolar passageiros e desinfetar cargas de navios, procurando evitar a disseminação de epidemias no país. Em 1942, suas edificaçôes foram aproveitadas pela Colônia Penal Cândido Mendes, que ficou ativa até 1962 . O prédio do Lazareto foi utilizado como prisão política em diversos momentos da história da nação.

${ }^{4}$ A estrada foi construída durante o regime militar, entre 1973 e 1975.

${ }^{5}$ Sobre as duas tentativas anteriores de instalação da Colônia Correcional de Dois Rios, na Ilha Grande, ver Santos 2004.

${ }^{6}$ Sobre a reforma do Serviço Policial do Distrito Federal, ver Bretas 1997. Os Decretos Legislativos 1631, de 03/01/1907, e 6440, de 30/03/1907 regulamentam a questão. 
${ }^{7}$ Decreto 6.994, de 19/06/1908, em conformidade com o Decreto 1.872, de 29/05/1908 e para execução do Decreto Legislativo 145, de 12/07/1903, e Lei 947, de 29/12/1902.

${ }^{8}$ Relatório do Ministro da Justiça e Negócios Interiores Esmeraldino Olympio de Torres Bandeira, de 1910, sobre o ano de 1909. Sobre o envio de menores reincidentes para a Colônia, ver Vianna 1999.

${ }^{9}$ No Relatório do Ministro da Justiça e Negócios Interiores Esmeraldino, Dr. Rivadávia da Cunha Correa, de 1911, solicita-se aumento dos vencimentos para os funcionários que se encontram segregados de todas as vantagens desfrutadas por aqueles que vivem nos grandes centros. Ver Arquivo Nacional Fundo IJ7.

${ }^{10}$ Arquivo Nacional, Série Justiça, Notação IJ7.

${ }^{11}$ Série Justiça. MJNI. Fundo IJ7. Arquivo Nacional.

12 Ibid.

${ }^{13}$ Para uma análise do ritual de fuga na Ilha Grande em períodos mais recentes, ver Santos 2004b, 2005.

${ }^{14}$ Para uma análise da modernização da estrutura jurídico-penal, ver, entre outros, Foucault 1975, Morris 1995, Rothman 2002, Caimari 2004.

${ }^{15}$ Grande parte destes documentos encontra-se no Arquivo Nacional, Série Justiça, Notação IJ7.

${ }^{16}$ É interessante observar que, em período bem posterior, também foi detectada a tentativa de inibição do desvio irregular dos mantimentos destinados aos internos. Em entrevistas realizadas em 2002, tanto Inair de Souza Pereira, o ex-diretor da Penitenciária Cândido Mendes, como a Dra. Julita Lengruber, apontaram o desvio dos suprimentos alimentares destinados aos internos como uma das causas do alto custo de manutenção da penitenciária e de sua desativação. Ver Santos 2005.

${ }^{17}$ Série Justiça. MJNI. Fundo IJ6. Arquivo Nacional.

${ }^{18}$ Ver, por exemplo, Pedroso s/d, Salla 1999.

${ }^{19}$ Estas leis são denunciadas por historiadores que analisam o início do período republicano. Ver, entre outros, Badaró 1991, Menezes 1996, Chalhoub 2001. Seria importante, entretanto, um estudo mais aprofundado da implicação destas leis na configuração das estruturas econômicas e sociais do presente.

${ }^{20}$ Ver Código Penal de 1890, Capítulo XIII: Dos Vadios e Capoeiras, Art. 399. Deixar de exercitar profissão, ofício, ou qualquer mister em que ganhe a vida, não possuindo meios de subsistência e domicílio certo em que habite; prover a subsistência por meio de ocupação proibida por lei, ou manifestamente ofensiva da moral e dos bons costumes: Pena de prisão celular por quinze a trinta dias. $\$ 1^{\circ}$ Pela mesma sentença que condenar o infrator como vadio, ou vagabundo, será ele obrigado a assinar termo de tomar ocupação dentro de 15 dias, contados do cumprimento da pena.

${ }^{21}$ Augusto Thompson (1993) é um dos autores que denuncia o artigo 59 das Leis das Contravençōes Penais, por ser contraditório à Constituição, que garante que todos são 
iguais perante a lei. O artigo condena de vadiagem apenas os pobres, pois os ricos, mesmo que não trabalhem, como apresentam meios de subsistência, não são penalizados.

22 Petit 1984, Morris 1995, Rothman 2002 e Caimari 2004.

${ }^{23}$ Ver o relatório do Chefe de Polícia Belisário Távora ao Ministro da Justiça e Negócios Interiores, Dr. Rivadávia da Cunha Correa, de 1912, relativo ao ano de 1911.

${ }^{24}$ Sobre a criação de asilos para pobres (Almshouse) no século XIX, ver Rothman 2002: 180-205. Segundo o autor, em 1840, havia 180 asilos para pobres em Massachusetts abrangendo 17.000 acres de terra (Rothman 2002:183).

${ }^{25}$ Em seu artigo 52, o Decreto 6.994, de 19/06/1908, que reorganiza a CCDR, define que seriam os internos da CCDR, com base no Código Penal de 1890, na Lei 947, de 29/12/1902 e no Decreto Legislativo 145, de 11/07/1893.

${ }^{26}$ Arquivo Nacional, Série Justiça, Notação IJ7.

${ }^{27}$ João do Rio. A Alma Encantadora das Ruas. www.terra.com.br/virtualbooks, p. 131.

${ }^{28}$ Lei n 628, 25/10/1899. "Lei Alfredo Pinto”. Artigo 6º "Compete ao chefe e delegados de polícia do Distrito Federal processar ex-officio as contravençóes do livro III, capítulos II e III, artigos 369 a 371 e 374, IV, V, VI, VIII, XII e XIII, art. 399, princípio, \$1º do Código Penal.

${ }^{29}$ Série Justiça. MJNI. Fundo IJ7. Arquivo Nacional.

${ }^{30}$ Entre os juristas que defenderam as novas abordagens científicas acerca do crime, ao longo da Primeira República, Alvarez (2002) cita Clóvis Beviláqua, José Higino, Paulo Egídio de Oliveira Carvalho, Raimundo Pontes de Miranda, Viveiros de Castro, Aurelino Leal, Cândido Mota, Moniz Sodré de Aragão, Evaristo de Moraes, José Tavares Bastos, Esmeraldino Bandeira e Lemos de Brito.

${ }^{31}$ Ver, por exemplo, a associação que Lemos Brito (1946) fez entre negros e traços anatômicos e psicológicos de criminosos através de uma análise da literatura nacional. A denúncia da influência das idéias lombrosianas no Brasil e de que idéias discriminatórias da antropologia criminal foram capazes de minar o valor formal da igualdade perante a lei no Brasil está presente em vários autores. Ver Fry 1985, Salla 1999, Alvarez 2002.

32 Sobre o papel do estigma e manipulação de identidade em instituições totais, ver Goffman $1961,1963$.

33 "A diminuição do efetivo dos correcionais, a partir de 1909, muito tem concorrido para a decadência da Colônia, no tocante à improdutividade do trabalho colonial. Semelhante decréscimo não se explica pela inércia policial, como poderia insinuar uma crítica sem bases, porquanto o movimento repressivo das contravenções prosseguiu com tenacidade maior em 1911, elevando-se a 3.601 o número das processadas nas delegacias distritais. Observa-se como sendo causas determinantes do excesso das saídas em relação às entradas dos correcionais, a praxe firmada pelo Poder Judiciário da aplicação das penas no grau mínimo, ainda mesmo quando sejam vadios reincidentes contra o disposto no art. 400 do Código Penal, e o fato das absolvições em massa proferidas sistematicamente por alguns pretores sempre que as testemunhas arroladas são agentes policiais”. Relatório 
do Chefe de Polícia, anexo ao relatório do Ministro da Justiça e Negócios Interiores, Dr Rivadávia da Cunha Correa, de 1912, relativo aos anos de 1911 e 1912, página 88.

${ }^{34}$ Ver o Relatório do Ministro da Justiça e Negócios Interiores, Dr. Rivadávia da Cunha Correa, de 1912, relativo aos anos de 1911 e 1912.

${ }^{35}$ Ver o Relatório do Ministro de Justiça e Negócios Interiores, Dr. Herculano de Freitas, de 1913, que contém relatório anexo do Chefe de Polícia Francisco do Campo Valladares. ${ }^{36}$ A Lei 2.964, de 05/01/1915, foi responsável por uma reforma policial, dentro do orçamento vigente, transformando a Segurança Pública em Seção de Investigação e Segurança e fortalecendo a repressão política. Ficou conhecida como Reforma Aurelino.

${ }^{37}$ A Lei 3.454, de 06/01/1918, fortaleceu o Corpo de Investigação e Segurança Pública do Serviço Policial do Distrito Federal ao consignar verbas de diligência policial para o aumento de pessoal encarregado pelo serviço de investigação e prisão política.

${ }^{38}$ Ver Decreto 12.690, de 27/10/1917 e 12.726, de 28/11/1917.

${ }^{39}$ Ver, por exemplo, depoimento do bacharel Arthur Vieira Peixoto, diretor da Casa de Correção, em 1917, em relatório detalhado enviado ao Ministro da Justiça: "sendo 'a correção moral a base e o fim exclusivo de toda atividade penal', como disse Carlos Roder, pergunto eu, como conseguir tão alevantado e grandioso objetivo sem a instituição do trabalho obrigatório, metódico, útil e produtivo, que é, incontestavelmente, o mais eficaz de todos os meios empregados para a consecução de semelhante objetivo? Será possível obter-se a regeneração moral dos condenados, indivíduos na sua maior parte desprovidos de bons sentimentos e, o que é pior, muito mais grave, dotados das mais vis paixões, deixando-os na mais completa e enervante ociosidade? Não tenho dúvida em afirmar que não há duas opiniōes a respeito: - tal procedimento seria um verdadeiro crime.” Relatório do MNJN Dr. Carlos Maximiliano Pereira dos Santos, de 1918. No relatório ministerial do ano de 1922, há a informação de que o diretor não foi capaz de manter a ordem na Casa de Correção e que foi substituído pelo coronel Artur de Meira Lima em dezembro de 1921, sofrendo inquérito por irregularidades administrativas.

${ }^{40}$ É interessante comparar a tentativa de legalização dos métodos repressivos com a legislação social criada no mesmo período. Ver Gomes 1979.

${ }^{41}$ Relatório do MJNI Dr. Alfredo Pinto Vieira de Mello, de junho de 1920, páginas VIII e IX.

${ }^{42}$ Relatório do MJNI Dr. Alfredo Pinto Vieira de Mello, de junho de 1920, página XXXVI.

${ }^{43}$ A Lei 4.269, de 17/01/1921, regulou a repressão ao anarquismo. Foi utilizada, entretanto, para repressão de movimentos diversos considerados contra a ordem. A lei condenava à prisão celular por um a quatro anos aqueles que provocassem diretamente, por escrito ou por qualquer outro meio de publicidade, ou verbalmente em reuniōes realizadas nas ruas, teatros, clubes, sedes de associaçōes, ou quaisquer lugares públicos ou franqueados ao público, a prática de crimes tais como dano, depredação, incêndio, homicídio, com o fim de subverter a atual organização social.

${ }^{44}$ Art. 50 do Código Penal: "O condenado a prisão celular por tempo excedente de seis anos e que houver cumprido metade da pena, mostrando bom comportamento, poderá

TOPOI, v. 7, n. 13, jul.-dez. 2006, pp. 445-476. 
ser transferido para alguma penitenciária agrícola, afim de aí cumprir o restante da pena." (...) Art. 52: "O livramento condicional será revogado, se o condenado cometer algum crime que importe pena restritiva da liberdade, ou não satisfizer a condição imposta. ..." ${ }^{45}$ O Decreto 14.079, de 25/02/1920, regulamentou a Inspetoria de Investigação e Segurança Pública, estabelecendo que o órgão seria uma instituição autônoma subordinada diretamente ao Chefe de Polícia. À Inspetoria competia o serviço de prevenção, investigação e vigilância e os serviços de proteção aos direitos individuais e de manutenção da ordem pública.

${ }^{46}$ Decreto n. 3.975 de 31 de dezembro de 1919.

${ }^{47}$ Ver Lei 4.242, de 1921.

${ }^{48}$ Decreto n. ${ }^{\circ} 4.577$, de 5 de setembro de 1922.

${ }^{49}$ Ver "Relatório dos Indivíduos Condenados à Internação na Colônia Correcional de Dois Rios, de 1903 a 1930"

${ }^{50}$ Relatório do MJNI João Luiz Alves, de junho de 1923.

${ }^{51}$ Ver Lemos Brito, 1924.

52 Relatório do Chefe de Polícia Fontoura, incluído no relatório do Ministro João Luiz Alves, de junho de 1924, página 190.

53 Segundo Fausto (1977), os tenentes foram condenados segundo o Decreto de 4.269, que, como vimos, fora promulgado em 1921 visando atingir o movimento anarquista.

${ }^{54}$ Lei 4.743, de 31/10/1923.

${ }^{55}$ Relatório do Chefe de Polícia sobre a Inspetoria da Polícia Marítima, anexo ao relatório do MJNI João Luiz Alves, de junho de 1923, página 187.

56 O Decreto-Lei no. 16.784, de 15 de janeiro de 1925, designa o Lazareto da Ilha Grande como prisão militar privativa, subordinada ao Ministério da Guerra. Em 14 de abril de 1927, o presidente Washington Luís determinou a extinção daquela prisão pelo Decreto-Lei no. 17.772 .

57 Desde finais da década de 1910 havia planos governamentais de ocupar regiões fronteiriças localizadas no Oiapoque, território do Amapá, por meio de colônias agrícolas. Em 5 de maio de 1922, foi inaugurada oficialmente, em plena selva amazônica, a colônia denominada Cleveland ou Clevelândia, ligada ao Ministério da Agricultura. A colônia recebeu inicialmente dezenas de famílias de trabalhadores nacionais e, posteriormente, presos comuns e políticos (Samis 2002: 158-162).

${ }^{58}$ Em 1925, a Colônia Cleveland contava com inúmeros deportados que haviam chegado em grandes levas: 419 presos, condenados por crimes comuns e políticos, chegaram do Rio de Janeiro em 1924; 119 marinheiros da revolta do Amazonas chegaram no início de 1925; e 408 soldados de baixa patente oriundos dos levantes de Catanduvas (Samis 2002).

${ }^{59}$ Citado por Samis 2002:167.

${ }^{60}$ Ver Relatório do Ministro da Justiça e Negócios Interiores, Dr. Augusto de Vianna do Castelo, de 1928, pág. 172-3. 


\section{FONTES PRIMÁRIAS E REFERÊNCIAS BIBLIOGRÁFICAS}

\section{Fontes Primárias}

ARQUIVO NACIONAL:

BRASIL. Ministério da Justiça e Negócios Interiores (Relatórios Ministeriais apresentados aos Presidentes da República, de 1896 a 1930)

Fundo: Série Justiça. MJNI. $\mathrm{IJ}^{2}$; $\mathrm{IJ}^{6}$; $\mathrm{IJ}^{7}$

COLEÇÃO DE LEIS BRASILEIRAS (CLB)

\section{Referências Bibliográficas}

ALVAREZ, Marcos César. A Criminologia no Brasil ou como Tratar Desigualmente os Desiguais. Revista Brasileira de Ciências Sociais, v. 45, n. 4, pp. 677704, 2002.

BADARÓ, Marcelo. Vadios, mendigos e bêbados na cidade do Rio de Janeiro do início do século. Tese de mestrado apresentada ao Programa de Pós-Graduação em História da Universidade Federal Fluminense. Niterói, 1991.

BRETAS, Marcos. Ordem na Cidade: O Exercício Cotidiano da Autoridade Policial no Rio de Janeiro, 1907-1930. Rio de Janeiro: Rocco, 1997.

CAIMARI, Lila. Apenas un Delincuente: Crimen, Castigo y Cultura en la Argentina, 1880-1955. Buenos Aires: Siglo XXI Editores Argentina, 2004.

CHALHOUB, Sidney. Trabalho, Lar e Botequim: O Cotidiano dos Trabalhadores no Rio de Janeiro da Belle Époque. Campinas, SP: Editora da Unicamp, 2001.

FAUSTO, Boris. A Crise dos Anos 20 e a Revolução de 1930. In FAUSTO, Boris (org.) HGCB. O Brasil Republicano, v. 3. São Paulo: DIFEL. 1977.

FOUCAULT, Michel. Surveiller et Punir: Naissance de la Prison. Paris: Gallimard, 1975.

FRY, Peter. Direito Positivo versus Direito Clássico: A Psicologização do Crime no Brasil no Pensamento de Heitor Carrilho. In: FIGUEIRA, Servulo (org.) A Cultura da Psicanálise. São Paulo: Brasiliense, 1985.

GOFFMAN, E. Asylums; essays on the social situation of mental patients and other inmates. Garden City, New York: Anchor Books, 1961.

GOFFMAN, E. Stigma; notes on the management of spoiled identity. Englewood Cliffs, New Jersey: Prentice-Hall, 1963. 
GOMES, Angela Maria de Castro. Burguesia e Trabalho: Política e Legislação Social no Brasil, 1917-1937. Rio de Janeiro: Campus, 1979.

JOÃO DO RIO. A Alma Encantadora das Ruas. www.terra.com.br/virtualbooks, s/d.

LEMOS BRITTO, J. G. Os Systemas Penitenciarios do Brasil. Rio de Janeiro: Imprensa Nacional, 1924.

LEMOS BRITTO, J. G. Os crimes e os Criminosos na Literatura Brasileira. Rio de Janeiro: José Olympio, 1946.

LIMA, Honório de. Notícia Histórica e Geográfica de Angra dos Reis. Rio de Janeiro: Livraria São José, 1889.

MELLO, Carl Egbert Hansen Vieira de. Apontamentos para Servir à História Fluminense: Ilha Grande, Angra dos Reis. Angra dos Reis: Conselho Municipal de Cultura, Prefeitura de Angra dos Reis, 1987.

MENEZES, Lená Medeiros. Os Indesejáveis: Desclassificados da Modernidade. Protesto, Crime e Expulsão na Capital Federal (1890-1930). Rio de Janeiro: EDUERJ, 1996.

MOREL, Edgar. A Revolta da Chibata. Rio de Janeiro: Graal, 1979.

MORRIS, Norval e David J. Rothman. The Oxford History of the Prison: The Practice of Punishment in Western Society. New York: Oxford University Press, 1995.

PEDROSO, Regina Célia. Utopias penitenciárias: Projetos jurídicos e realidade carcerária no Brasil. http://www1.jus.com.br/doutrina, s/d.

PETIT, Jacques G. (ed.). La Prison, le bagne et l'histoire. Paris, Genève: Libr. des Méridiens, 1984.

ROTHMAN, David J. The Discovery of the Asylum: Social Order and Disorder in the New Republic. New York: Aldine de Gruyte, 2002.

SALLA, Fernando. As Prisões em São Paulo: 1822-1940. São Paulo: Annablume, 1999.

SAMIS, Alexandre. Clevelândia: Anarquismo, Sindicalismo e Repressão Política no Brasil. São Paulo: Editora Imaginário/Achiamé, 2002.

SANTOS, Myrian Sepúlveda. A Prisão dos Ébrios, Capoeiras e Vagabundos no Início da Era Republicana. Topoi Revista de História, v. 5, n. 8, pp. 138-169, 2004. SANTOS, Myrian Sepúlveda. História e Memória: o Caso do Ferrugem. Revista Brasileira de História, v. 23, n. 46, pp. 271-295, 2004 b.

SANTOS, Myrian Sepúlveda. A Construção da Violência: O Caso da Ilha Grande. In: PRADO, Rosane Manhães (org). Ilha Grande: Do Sambaqui ao Turismo. Rio de Janeiro: EDUERJ (prelo), 2005. 
THOMPSON, Augusto. A Questão Penitenciária. Rio de Janeiro: Editora Forense, 1993.

VIANNA, Adriana de Resende. O mal que se Adivinha. Rio de Janeiro: Arquivo Nacional, 1999.

\section{RESUMO}

Este artigo tem como objetivo investigar a consolidação da Colônia Correcional de Dois Rios (CCDR), na Ilha Grande, entre os anos de 1908 e 1930. A Colônia recebeu os pequenos contraventores que perambulavam pela cidade, mas também, quando necessário, um número grande de presos políticos, entre eles, estrangeiros, que se tornavam uma ameaça devido ao fortalecimento do movimento anarquista. A história dessa instituição nos mostra uma tensão constante entre o teor da lei e práticas autoritárias, entre princípios liberais e positivistas, bem como entre o discurso da ordem e uma violência arbitrária e sem controle associada às práticas punitivas, direcionadas aos setores menos favorecidos da sociedade.

Palavras-chave: Primeira República, Rio de Janeiro, Ilha Grande, Presidio, Penitenciária, violência.

\section{ABSTRACT}

The objective of this article is to investigate the consolidation of a penitentiary establishment called "Colônia Correcional de Dois Rios", at Ilha Grande, Rio de Janeiro, between the years 1908 and 1930. During this period, the Colonia received the small buglers who populated the streets of the city, but also, when necessary, all political prisoners, foreigners, who had become a menace due to the strengthening of anarchist movements, and members of popular manifestations e political movements against the political regime. The history of this institution indicates a constant tension between liberal and positivist principles, the law and authoritarian practices, as well as between official narratives on order and arbitrary and uncontrolled practices of punishment, directed towards those individuals without any sort of social privileges and assistance.

Key-words: First Brazilian Republic, Rio de Janeiro, Ilha Grande, Prison, Penitentiary, violence. 